\title{
Absolute transition probabilities of AI I and AI II spectral lines and intensity ratios within multiplets ${ }^{\star}$
}

\author{
V. Vujnović ${ }^{1}$, K. Blagoev ${ }^{2}$, C. Fürböck ${ }^{3}$, T. Neger ${ }^{3}$, and H. Jäger ${ }^{3}$ \\ 1 Institute of Physics of the University, PO Box 304, HR-10001 Zagreb, Croatia \\ 2 Institute of Solid State Physics, Bul. Tzarigradsko Chaussee 72, 1784 Sofia, Bulgaria \\ 3 Institut für Experimentalphysik, Technische Universität Graz, Petersgasse 16, 8010 Graz, Austria \\ Received 29 September 1997 / Accepted 19 March 2002
}

\begin{abstract}
Relative intensity measurements of $\mathrm{AlI}$ and $\mathrm{AlII}$ spectral lines in the visible and ultraviolet spectral ranges are performed using a capacitively coupled high frequency double hollow electrode discharge. Branching ratios and intensity ratios within multiplets are determined. By using selected lifetimes absolute transition probabilites are calculated.
\end{abstract}

Key words. atomic data - lines: formation - methods: laboratory

\section{Introduction}

Spectral lines of neutral and singly ionized aluminum can be observed in numerous laboratory experiments and are also found in many stellar spectra. Although a number of studies were devoted to lifetimes of upper levels and oscillator strengths of aluminum lines, the availability of reliable data is far from being satisfactory.

In this work a stable source with non-thermal excitation was used for precise relative intensity measurements. We report on measurements of relative intensities of spectral lines of neutral and singly ionized aluminum. The obtained results were partly used to inspect relative intensities within multiplets, i.e. either to justify the ratios expected for $L S$ coupling, or to reveal deviations from these theoretically expected ratios. In case of available lifetimes and branching ratios, measured as completely as possible, absolute transition probabilities were evaluated.

\section{Experimental}

\subsection{The hollow cathode rf-discharge}

As a light source a capacitively-coupled $r f$-plasma was produced in a cylindrical chamber, which contained two cylindrical aluminum electrodes. One of these electrodes was grounded, the other one was put at $r f$-high-voltage, which was produced by a high-frequency generator (Crespo Lopez-Urrutia et al. 1994). The discharge burned in direct

\footnotetext{
Send offprint requests to: T. Neger, e-mail: t.neger@iep.tu-graz.ac.at

* The tables are also available in electronic form at the CDS via anonymous ftp to cdsarc.u-strasbg.fr (135.79.128.5) or via

http://cdsweb.u-strasbg.fr/cgi-bin/qcat?J/A+A/388/704
}

contact with the electrodes, therefore electrode material was sputtered off by ions and electrons. During the highfrequency period the electrodes act as hollow cathodes as well as hollow anodes, depending on their momentary polarity.

In the chosen frequency region the electrons are able to follow the changes of the electric field in phase. High sputtering rates are reached by their relatively high kinetic energy. On the other hand, the electron movement is a reason for a negative $d c$-voltage of the electrodes compared to the plasma. This negative self bias is a typical feature of $r f$-discharges. It is the reason for an almost steady bombardment of the electrode surfaces with gas ions produced in the plasma.

Since the ions reach energies of several hundreds of eV during their acceleration in the negative bias region, a sufficient sputtering rate of aluminum atoms out of the electrode surface can be achieved. These atoms are ionized by collisions with electrons or charge exchange processes. Compared with dc-discharges, significantly higher excitation stages are within reach in case of $r f$-conditions, because the high voltage peak values do not have to be maintained constantly. Moreover, the thermal stress of the electrodes is reduced by a very homogeneous current distribution over the electrode surface, a low operating pressure with an increased current density characterizes this discharge type.

The rf-generator was a home-made construction, which favours the choice of optimal electrical parameters (Crespo Lopez-Urrutia et al. 1994). It is tunable in the region from 11 to $28 \mathrm{MHz}$ and operated in the C-mode with a BBC ITK 12-1 water-cooled power triode. Although the rated output $\mathrm{cw}$-power was $20 \mathrm{~kW}$, only an input power 
of $1.5 \mathrm{~kW}$ was applied in case of the capacitively coupled plasma, since a resonance transformer had to be used in order to produce a sufficiently high voltage. The generator was connected to a $r$-matching box, a $50 \Omega$ coaxial line led to the discharge chamber. This line consisted of two copper tubes (outer diameter $54 \mathrm{~mm}$, inner diameter $18 \mathrm{~mm}$ ) with teflon spacers fixing them at a distance.

The discharge vessel is mounted to the matching box, which contains the resonance transformer. To prevent undesirable sparks, this box was filled with $\mathrm{SF}_{6}$ at a pressure of approx. 1.5 bar. With a variable vacuum capacitor the matching box was tuned to provide the desired power rate for the discharge. The length of the hollow electrodes was 20-40 $\mathrm{mm}$, the holes in the electrodes had a diameter of $3.5 \mathrm{~mm}$.

The discharge was operated at pressures between 2 and 20 mbar in a power range between 0.7 and $1.3 \mathrm{~kW}$. It burned stably for several hours, which allowed lengthy detection scans. Helium was used as a buffer gas with a continuous flow rate of a few liters per hour. This flow favoured the reduction of dirt deposition on the quartz windows at the discharge chamber being used for end-on observation. The power deposition into the discharge was monitored calorimetrically.

\subsection{The detection of the optical radiation}

By use of two concave surface mirrors the plasma was imaged on the entrance slit of a McPherson monochromator (type 209, $1.33 \mathrm{~m}$ focal length). This monochromator was equipped with a Czerny-Turner mounting and a holographic grating (2400 lines/mm). So it was possible to resolve a $F W H M$ down to $0.06 \AA$ in first order, a spectral range from 1900 to $6500 \AA$ could be covered. The widths of the entrance and exit slits were adjusted for optimal resolution. The height of the entrance slit was restricted to $2 \mathrm{~mm}$ to ensure an axial detection of the plasma.

The radiation was recorded using a fast photomultiplier (EMI $9558 \mathrm{QB}$ ) being connected to a photon counting system (Stanford Research SR 400). This arrangement offered a high dynamic range together with a very high signal/noise ratio. The spectral sensitivity was calibrated using an Argon Mini Arc of the National Institute of Standards and Technology for wavelengths between 1900 and $4000 \AA$, at longer wavelengths a tungsten strip lamp was used. Since the maximum photon-counting rate was about $5 \mathrm{MHz}$, deviations from linear response caused by dead-time and pile-up effects in the multiplier could be reliably avoided.

By use of a personal computer the photon counter and the step motor for the wavelength scan could be controlled simultaneously via an RS-232 interface. This arrangement provided a full-automatic data aquisition.

The used ultraviolet and visible spectral ranges are well suited for the observation of the spectrum of neutral aluminum, since - owing to the low ionization energy it shows no spectral lines with wavelengths shorter than
$2000 \AA$ A. For both neutral and singly ionized aluminum, an extension of the observation region towards the infrared, however, would increase the number of completely measurable branching fractions.

\section{Lifetimes}

We made a review of the published lifetimes and oscillator strengths. In the case of neutral aluminum, the lifetimes were measured by the Hanle effect, hook, beam foil, phase shift and LIF techniques, and calculated by several authors. Many measurements were undertaken of $4 \mathrm{~s}$ and $3 \mathrm{~d}$ lifetimes, and s, p, d level series were experimentally covered in a wide range: $n$ s for $n=4-10$ (Jönsson \& Lundberg 1983; Buurman et al. 1986), $n \mathrm{p}$ for $n=4-12$ (Buurman et al. 1986; Jönsson et al. 1984), $n$ d for $n=3-13$ (Jönsson \& Lundberg 1983; Buurman et al. 1986; Davidson et al. 1990). For the $n f$ levels only theoretical values exist (Theodosiou 1992).

In the framework of the Opacity Project (OP) (Mendoza et al. 1995) a large number of transition probabilities of allowed transitions and radiative lifetimes of Al I excited levels were calculated. These values agree well with experimental data. There is a difference for $(3 \mathrm{~d}, 4 \mathrm{~d})$ excited states with theoretical data of C. E. Theodosiou (Theodosiou 1992), since in the latter paper the electron configuration interaction effect (CI) had not been taken into account. This effect originates from the influence of all $n$ d series by the $3 \mathrm{~s} \mathrm{p}^{2}{ }^{2} \mathrm{D}$ level, but mainly of the low lying $3 \mathrm{~d}, 4 \mathrm{~d}$ levels. Theoretical works must also be mentioned in which, employing different approaches, oscillator strengths of $3 \mathrm{~s}^{2} 3 \mathrm{p}{ }^{2} \mathrm{P}-3 \mathrm{~s}^{2} 3 \mathrm{~d}{ }^{2} \mathrm{D} ; 3 \mathrm{~s}^{2} 4 \mathrm{~s}{ }^{2} \mathrm{~S}$ and $3 \mathrm{~s}^{2} 4 \mathrm{~s}{ }^{2} \mathrm{~S}-3 \mathrm{~s}^{2} 4 \mathrm{p}^{2} \mathrm{P}$ were calculated (Lavin et al. 1997; Ozdemir \& Karal 1997). In CI approximation, oscillator strengths of 11 transitions were obtained (Marcinek \& Migdalek 1993), including $3 \mathrm{~s}^{2} 3 \mathrm{p}^{2} \mathrm{P}-\left(3 \mathrm{~s} 3 \mathrm{~d}, 3 \mathrm{~s} 3 \mathrm{p}^{2}\right)^{2} \mathrm{D}$ transitions.

Although the Al I spectrum is rich in spectral lines originating from the complex part of the term diagram, only the lifetimes of the levels $3 \mathrm{~s} 3 \mathrm{p}^{2}{ }^{2} \mathrm{P}_{1 / 2,3 / 2}$, which are also liable to autoionization, were measured (Lombardi et al. 1981).

Experimental data for radiative lifetimes of singly ionized aluminum are scarce in literature. They were calculated for the $n f \mathrm{~F}^{\circ}$ levels $(n=4-7)$ in the simple part of the energy diagram, and for the $3 \mathrm{p} 3 \mathrm{dF}$ level in the complex part (Chang \& Wang 1987). For the same F levels lifetimes were measured by the beam-foil technique (Andersen et al. 1971), unfortunately with low precision.

In CI approximation the radiative lifetimes of a large number of excited levels of Al II were calculated (Chang \& Fang 1995), namely $3 \mathrm{~s} n \mathrm{~s}{ }^{1,3} \mathrm{~S}(n=4-6)$; 3s $n \mathrm{p}{ }^{1,3} \mathrm{P}$; $3 \mathrm{~s} n \mathrm{~d}^{1,3} \mathrm{D} ; 3 \mathrm{p}^{21} \mathrm{~S}, 3 \mathrm{p}^{21} \mathrm{D}$ levels. The main part of the papers, however, are dedicated to radiative lifetimes of singlet and triplet $3 \mathrm{p}^{1,3} \mathrm{P}$ levels. Radiative lifetime of the $3 \mathrm{p}^{3} \mathrm{P}_{1}^{\mathrm{o}}$ level was measured in a storage ring (Trabert et al. 1999) and in a ion trap experiment (Johnson et al. 1986). The obtained data are in excellent agreement (within a $1 \%$ limit). 
Table 1. Lifetimes $(\tau)$ of neutral and ionized aluminum. If more than one source is cited, an average of the lifetimes was taken.

\begin{tabular}{|c|c|c|c|c|c|}
\hline \multicolumn{3}{|r|}{$\overline{\mathrm{Al} \mathrm{I}}$} & \multicolumn{3}{|c|}{$\overline{\mathrm{Al} \mathrm{II}}$} \\
\hline Level des. & $\tau / n \mathrm{~s}$ & Source & Level des. & $\tau / n \mathrm{~s}$ & Source \\
\hline $3 \mathrm{~s}^{2} 4 \mathrm{~s}^{4} \mathrm{~S}_{1 / 2}$ & $6.85(6)$ & $\begin{array}{l}\text { Buurman et al. (1986) } \\
\text { Klose (1997) }\end{array}$ & $3 \mathrm{p}^{1} \mathrm{P}_{1}^{\mathrm{o}}$ & $0.690(13)$ & $\begin{array}{l}\text { Kernahan et al. (1979) } \\
\text { Smith (1970) }\end{array}$ \\
\hline $3 \mathrm{~s}^{2} 5 \mathrm{~s}{ }^{4} \mathrm{~S}_{1 / 2}$ & $19.8(5)$ & Buurman et al. (1986) & & & Berry et al. (1970) \\
\hline $3 \mathrm{~s}^{2} 4 \mathrm{p}^{2} \mathrm{P}_{1 / 2}^{\mathrm{o}}$ & $60.5(9)$ & Buurmann \& Dönszelmann (1990) & & & Head et al. (1976) \\
\hline $3 \mathrm{~s}^{2} 4 \mathrm{p}^{2} \mathrm{P}_{3 / 2}^{\mathrm{o}}$ & $65(2)$ & Buurmann \& Dönszelmann (1990) & $3 \mathrm{p}^{3} \mathrm{P}_{1}^{\mathrm{o}}$ & $302(2) \times 10^{3}$ & Trabert et al. (1999) \\
\hline $3 \mathrm{~s}^{2} 5 \mathrm{p}^{2} \mathrm{P}_{1 / 2,3 / 2}^{\mathrm{o}}$ & $275(8)$ & Buurman et al. (1986) & & & Johnson et al. (1986) \\
\hline $3 \mathrm{~s}^{2} 3 \mathrm{~d}^{2} \mathrm{D}_{3 / 2,5 / 2}$ & $14.0(2)$ & Buurman et al. (1986) & $4 \mathrm{f}^{3} \mathrm{~F}^{\mathrm{o}}$ & $6.4(5)$ & Andersen et al. (1971) \\
\hline $3 \mathrm{~s}^{2} 4 \mathrm{~d}^{2} \mathrm{D}_{3 / 2,5 / 2}$ & $29.5(7)$ & Buurman et al. (1986) & $5 \mathrm{f}^{3} \mathrm{~F}^{\mathrm{\prime}}$ & $14(2)$ & Andersen et al. (1971) \\
\hline $3 \mathrm{~s}^{2} 5 \mathrm{~d}^{2} \mathrm{D}_{3 / 2,5 / 2}$ & $13.2(3)$ & Davidson et al. (1990) & $6 \mathrm{f}^{3} \mathrm{~F}^{\mathrm{o}}$ & $15(1)$ & Andersen et al. (1971) \\
\hline $3 \mathrm{~s}^{2} 6 \mathrm{~d}^{2} \mathrm{D}_{3 / 2,5 / 2}$ & $14.0(2)$ & Davidson et al. (1990) & $7 \mathrm{f}^{3} \mathrm{~F}^{\mathrm{o}}$ & $5.0(5)$ & Andersen et al. (1971) \\
\hline & & & $3 \mathrm{~d}^{3} \mathrm{~F}_{2,3,4}^{\mathrm{O}}$ & $3.5(3)$ & Andersen et al. (1971) \\
\hline
\end{tabular}

The average experimental data are presented in Table 1. There are four experimental works in which, by use of the beam - foil method, the radiative lifetime of the singlet $3 \mathrm{p}{ }^{1} \mathrm{P}_{1}^{o}$ level was measured (Kernahan et al. 1979; Smith 1970; Berry et al. 1970; Head et al. 1976). The agreement of experimental data is within a $2 \%$ limit and the average experimental value is also presented in Table 1 . Radiative lifetimes of singlet and triplet $3 \mathrm{p}^{1,3 \mathrm{P}}$ levels are calculated in a number of theoretical papers (Jonsson \& FroeseFisher 1997; Zon \& Froese-Fisher 2001; Stanek et al. 1996; Chang \& Fang 1995; Chou et al. 1973; Das \& Idrees 1990; Huang \& Johanson 1985; Cowan et al. 1982; Chang \& Wang 1987; Hibbert \& Keenan 1987; Laughlin \& Victor 1979) some of them published recently. The agreement of theoretical data for the singlet $3 \mathrm{p}^{1} \mathrm{P}_{1}^{\mathrm{o}}$ level is very good (within a $3 \%$ limit) and there is also good agreement between experimental and theoretical data for this level. The theoretical results for the triplet $3 \mathrm{p}{ }^{3} \mathrm{P}_{1}^{\mathrm{o}}$ level agree within an $18 \%$ limit (except for data of Das \& Idrees (1990), where the value is 3 times smaller and probably due to a misprint) and the agreement with average experimental value is within a $5 \%$ limit. The theoretical calculations in the framework of Opacity Project also concern radiative constants of the Al II spectrum (Butler et al. 1993). The agreement of these data with experimental values is within $15 \%$ except for the $3 \mathrm{p}^{2}{ }^{1} \mathrm{D}$ level. The radiative constants of excited $\mathrm{Al} \mathrm{I}$ and $\mathrm{Al}$ II levels are included in the review of Fuhr \& Wiese (1996), where a critical compilation was made.

Singly ionized aluminum has prominent transitions between displaced and normal levels - as in the case for the neutral atom - and there is a need for experimental data. Employing the beam-foil method in the work of BaudinetRobinet et al. (1979) along with resonance $3 \mathrm{p}{ }^{1} \mathrm{P}_{1}$ and $3 \mathrm{~d}^{3} \mathrm{D}$ excited states, the $3 \mathrm{p}^{2}{ }^{3} \mathrm{P}_{1,2}$ states were measured using the $3 \mathrm{p}^{2}{ }^{3} \mathrm{P}_{1,2}-3 \mathrm{p}^{3} \mathrm{P}_{1}^{0}$ transition. The obtained data, however, are larger than results of other authors (Berry et al. 1970; Smith 1970). With respect to our branching ratio measurements an experimentally determined lifetime of the $3 \mathrm{p}^{2}{ }^{1} \mathrm{D}_{2}$ level would be of special importance.

We have selected the lifetimes (Table 1) of the upper levels of transitions which we measured. As criteria the reliability of the experimental method (laser induced fluorescence preferred), the consideration of the experimental conditions, the agreement between different authors' results, and the estimated uncertainties have been applied. For theoretical results a coincidence of the oscillator strengths and the corresponding lifetimes, obtained in the length and velocity formalism, may eventually serve as a sign of quality.

We obtained the lifetime of the $\mathrm{Al} \mathrm{I} 4 \mathrm{~s}$ level as an average of the values obtained by Klose (1997) and Buurman et al. (1986). In the same laboratory Buurmann \& Dönszelmann (1990) found deviations from the $L S$ expected equality of the lifetimes of the fine structure levels ${ }^{2} \mathrm{P}_{1 / 2},{ }^{2} \mathrm{P}_{3 / 2}$. The lifetime of $3 \mathrm{~d}$ equal to $14.0(2)$ ns was taken over from Buurman et al. (1986). It should be mention that the average of seven measurements (Jönsson \& Lundberg 1983; Buurman et al. 1986; Andersen et al. 1969; Cunningham 1968; Smith \& Liszt 1971; Marek \& Richter 1973; Hannaford \& Lowe 1981) is equal to 13.9 ns. This confirms the reliability of the $3 \mathrm{~d}$ lifetime within the stated accuracy.

\section{Discussion}

Table 2 contains the findings of intensity ratios and of transition probabilities of the simple Al I spectrum. The resonance doublet at $\lambda=3944$ and $3962 \AA$ is an example that demonstrates our procedure. The relative error of the transition probability is given as the sum of the relative errors of the ratio and of the lifetime. Taking the theoretical ratio, the transition probability would equal the error of the lifetime measurement (1\%).

The level $5 \mathrm{~s}$ has two decay channels, $5 \mathrm{~s}-3 \mathrm{p}$ and $5 \mathrm{~s}-4 \mathrm{p}$. Buurman et al. (1986) measured their branching ratios, without resolving the fine structure, with an error of $10 \%$. For $5 \mathrm{~s}-4 \mathrm{p}$ transitions we evaluated the transition probabilities assuming theoretical intensity ratios of the component lines.

The branching ratios of $4 \mathrm{p}-4 \mathrm{~s}, 4 \mathrm{p}-3 \mathrm{~d}$ were measured indirectly by (Buurmann \& Dönszelmann 1990). They found $2-3 \%$ of de-excitation going into the $3 \mathrm{~d}$ term. Accounting for this loss we obtained transition probabilities for the doublet $4 \mathrm{p}-4 \mathrm{~s}$ from respective lifetimes. 
Table 2. Al I-intensity ratios within multiplets, and transition probabilities for the simple part of the Grotrian diagram. According to Kaufman and Martin (Kaufman \& Martin 1991) the level $3 \mathrm{~s}^{2} 4 \mathrm{~d}^{2} \mathrm{D}$ is designated as $y \mathrm{D}$, and all higher $d$ levels acquire numbers for one less than previously ( $5 \mathrm{~d}$ goes to $4 \mathrm{~d}$, and so on).

\begin{tabular}{|c|c|c|c|c|c|c|c|c|c|c|c|}
\hline \multirow{2}{*}{$\begin{array}{l}\begin{array}{l}\text { Upper } \\
\text { level }\end{array} \\
3 \mathrm{~s}^{2} 4 \mathrm{~s}^{2} \mathrm{~S}_{1 / 2}\end{array}$} & \multirow{2}{*}{$\begin{array}{l}\begin{array}{l}\text { Lower } \\
\text { level }\end{array} \\
3 \mathrm{p}^{2} \mathrm{P}_{1 / 2}^{\mathrm{o}}\end{array}$} & \multirow{2}{*}{$\begin{array}{l}\lambda / \AA \\
3944.006\end{array}$} & \multicolumn{3}{|c|}{ Intensity ratio } & \multicolumn{2}{|c|}{$\begin{array}{l}\text { Branching } \\
\text { ratio }\end{array}$} & \multicolumn{2}{|c|}{ this work } & \multicolumn{2}{|c|}{$\begin{array}{c}A_{k i} / 10^{8} \mathrm{~s}^{-1} \\
\text { other authors }\end{array}$} \\
\hline & & & 0.48 & $9 \%$ & 0.5 & 0.325 & $9 \%$ & 0.47 & $10 \%$ & 0.493 & Wiese \& Martin (1980) \\
\hline & $3 \mathrm{p}^{2} \mathrm{P}_{3 / 2}^{\mathrm{o}}$ & 3961.520 & 1 & $5 \%$ & 1.0 & 0.675 & $5 \%$ & 0.99 & $6 \%$ & 0.98 & Wiese \& Martin (1980) \\
\hline \multirow[t]{4}{*}{$3 \mathrm{~s}^{2} 5 \mathrm{~s}^{2} \mathrm{~S}_{1 / 2}$} & $3 \mathrm{p}^{2} \mathrm{P}_{1 / 2}^{\mathrm{o}}$ & 2652.484 & 0.50 & $2 \%$ & 0.5 & & & 0.142 & $12 \%$ & 0.133 & Wiese \& Martin (1980) \\
\hline & $3 \mathrm{p}^{2} \mathrm{P}_{3 / 2}^{\mathrm{o}}$ & 2660.393 & 1 & $1 \%$ & 1.0 & & & 0.284 & $11 \%$ & 0.264 & Wiese \& Martin (1980) \\
\hline & $4 \mathrm{p}^{2} \mathrm{P}_{1 / 2}^{\mathrm{o}}$ & 21093.04 & & & 0.5 & & & 0.030 & $>30 \%$ & & \\
\hline & $4 \mathrm{p}^{2} \mathrm{P}_{3 / 2}^{\mathrm{o}}$ & 21163.75 & & & 1.0 & & & 0.060 & $>30 \%$ & & \\
\hline $3 \mathrm{~s}^{2} 4 \mathrm{p}^{2} \mathrm{P}_{1 / 2}^{\mathrm{o}}$ & $4 \mathrm{~s}^{2} \mathrm{~S}_{1 / 2}$ & 13150.76 & & & 0.5 & & & 0.160 & $3 \%$ & 0.169 & Buurman et al. (1986) \\
\hline $3 \mathrm{~s}^{2} 4 \mathrm{p}^{2} \mathrm{P}_{3 / 2}^{\mathrm{o}}$ & $4 \mathrm{~s}^{2} \mathrm{~S}_{1 / 2}$ & 13123.41 & & & 1.0 & & & 0.150 & $5 \%$ & 0.169 & Buurman et al. (1986) \\
\hline \multirow[t]{2}{*}{$3 \mathrm{~s}^{2} 3 \mathrm{~d}^{2} \mathrm{D}_{3 / 2}$} & $3 \mathrm{p}^{2} \mathrm{P}_{1 / 2}^{\mathrm{o}}$ & 3082.153 & 0.53 & $10 \%$ & 0.56 & 0.83 & $10 \%$ & 0.59 & $12 \%$ & 0.63 & Wiese \& Martin (1980) \\
\hline & $3 \mathrm{p}^{2} \mathrm{P}_{3 / 2}^{\mathrm{o}}$ & 3092.839 & $\approx 0$ & & 0.11 & 0.17 & & $(0.12)$ & & & \\
\hline \multirow{5}{*}{$\begin{array}{l}3 \mathrm{~s}^{2} 3 \mathrm{~d}^{2} \mathrm{D}_{5 / 2} \\
\mathrm{y}{ }^{2} \mathrm{D}_{3 / 2}\end{array}$} & $3 \mathrm{p}^{2} \mathrm{P}_{3 / 2}^{\mathrm{o}}$ & 3092.710 & 1 & $5 \%$ & 1 & $\equiv 1.00$ & & 0.71 & $2 \%$ & 0.74 & Wiese \& Martin (1980) \\
\hline & $3 \mathrm{p}^{2} \mathrm{P}_{1 / 2}^{\mathrm{o}}$ & 2567.984 & 0.51 & $9 \%$ & 0.56 & & & $<0.28$ & & 0.23 & Wiese \& Martin (1980) \\
\hline & & & & & & & & & & 0.192 & Davidson et al. (1990) \\
\hline & $3 \mathrm{p}^{2} \mathrm{P}_{3 / 2}^{\mathrm{o}}$ & 2575.393 & 0.12 & $25 \%$ & 0.11 & & & $<0.05$ & & 0.044 & Wiese \& Martin (1980) \\
\hline & & & & & & & & & & 0.038 & Davidson et al. (1990) \\
\hline \multirow[t]{2}{*}{$\mathrm{y}^{2} \mathrm{D}_{5 / 2}$} & $3 \mathrm{p}^{2} \mathrm{P}_{3 / 2}^{\mathrm{o}}$ & 2575.094 & 1 & $6 \%$ & 1 & & & $<0.34$ & & 0.28 & Wiese \& Martin (1980) \\
\hline & & & & & & & & & & 0.230 & Davidson et al. (1990) \\
\hline \multirow[t]{2}{*}{$3 \mathrm{~s}^{2} 5 \mathrm{~d}^{2} \mathrm{D}_{3 / 2}$} & $3 \mathrm{p}^{2} \mathrm{P}_{1 / 2}^{\mathrm{o}}$ & 2367.025 & 0.75 & $8 \%$ & 0.56 & & & $<0.63$ & & 0.72 & Wiese \& Martin (1980) \\
\hline & & & & & & & & & & 0.526 & Davidson et al. (1990) \\
\hline \multirow[t]{2}{*}{$(4 d)$} & $3 \mathrm{p}^{2} \mathrm{P}_{3 / 2}^{\mathrm{o}}$ & 2373.349 & 0.13 & $37 \%$ & 0.11 & & & $<0.13$ & & 0.14 & Wiese \& Martin 1980) \\
\hline & & & & & & & & & & 0.105 & Davidson et al. (1990) \\
\hline \multirow[t]{2}{*}{$3 \mathrm{~s}^{2} 5 \mathrm{~d}{ }^{2} \mathrm{D}_{5 / 2}$} & $3 \mathrm{p}^{2} \mathrm{P}_{3 / 2}^{\mathrm{o}}$ & 2373.124 & 1 & $7 \%$ & 1.00 & & & $<0.76$ & & 0.86 & Wiese \& Martin (1980) \\
\hline & & & & & & & & & & 0.631 & Davidson et al. (1990) \\
\hline \multirow[t]{4}{*}{$3 \mathrm{~s}^{2} 6 \mathrm{~d}{ }^{2} \mathrm{D}_{3 / 2}$} & $3 \mathrm{p}^{2} \mathrm{P}_{1 / 2}^{\mathrm{o}}$ & 2263.462 & 0.50 & $14 \%$ & 0.56 & & & $<0.59$ & & 0.66 & Wiese \& Martin (1980) \\
\hline & & & & & & & & & & 0.576 & Davidson et al. (1990) \\
\hline & $3 \mathrm{p}^{2} \mathrm{P}_{3 / 2}^{\mathrm{o}}$ & 2269.220 & $\approx 0$ & & 0.11 & & & $<0.12$ & & 0.13 & Wiese \& Martin (1980) \\
\hline & & & & & & & & & & 0.115 & Davidson et al. (1990) \\
\hline \multirow[t]{2}{*}{$3 \mathrm{~s}^{2} 6 \mathrm{~d}^{2} \mathrm{D}_{5 / 2}$} & $3 \mathrm{p}^{2} \mathrm{P}_{3 / 2}^{\mathrm{o}}$ & 2269.096 & 1 & $7 \%$ & 1.00 & & & $<0.71$ & & 0.79 & Wiese \& Martin (1980) \\
\hline & & & & & & & & & & 0.691 & Davidson et al. (1990) \\
\hline
\end{tabular}

Among the triplet $3 \mathrm{~d}-3 \mathrm{p}$ we could observe only the principal lines 3082.153 and $3092.710 \AA$; the transition probability of the line $3092.839 \AA$ was then obtained following the $L S$ intensity ratio. Since the transition $3092.710 \AA$ is a single decay channel from the level $3 \mathrm{~d}^{2} \mathrm{D}_{5 / 2}$, its transition probability is by definition equal to the reciprocal value of the lifetime and has got the same error of $2 \%$.

The intensity ratios within multiplets of the simple part of the Grotrian diagram closely follow $L S$ coupling ratios.

For some other $n \mathrm{p}-m \mathrm{~s}, n \mathrm{p}-m \mathrm{~d}, n \mathrm{~d}-m \mathrm{p}(n>m)$ transitions, theoretical multiplet oscillator strengths were published in Buurman et al. (1986); Weiss (1974); Taylor et al. (1988); Trefftz (1988), and experimental ones in Davidson et al. (1990).

The observed multiplets (septets) in the complex part of the $\mathrm{Al} \mathrm{I}$ spectrum (Table 3) have, in principle, components of very different intensities, therefore the accuracy is strongly dependent on the intensity.
Two of the multiplets show a severe decrease of the relative intensity for transitions having upper levels ${ }^{4} \mathrm{P}_{1 / 2,3 / 2}^{\mathrm{o}}$. The decrease is caused by autoionization, since these upper levels have the same orbital and inner quantum numbers and parity as the continuum $\varepsilon \mathrm{p}^{2} \mathrm{P}_{1 / 2,3 / 2}^{\circ}$. A weakening of the transitions $4 \mathrm{~s} 4 \mathrm{p}{ }^{4} \mathrm{P}_{1 / 2,3 / 2}^{\circ}-3 \mathrm{p}^{2}{ }^{4} \mathrm{P}$ was observed by Eriksson \& Isberg (1962). The decrease in intensity of autoionizing components is not so obvious in the case of the multiplet $3 \mathrm{~d}^{4} \mathrm{P}^{\circ}-3 \mathrm{p}^{2}{ }^{4} \mathrm{P}$ due to generally lower intensities of the transition from this higher term. In case of this multiplet only components not affected by autoionization obey the $L S$ coupling ratio. A property of all three multiplets is the absence of other transitions from their upper terms. By accounting for autoionization, branching ratios would immediately follow from the intensity ratios.

A very interesting deviation from the $L S$ coupling ratios is found in the multiplet $3 \mathrm{~d}^{4} \mathrm{D}^{\circ}-3 \mathrm{p}^{2}{ }^{4} \mathrm{P}$. The component $3 \mathrm{~d}^{4} \mathrm{D}_{7 / 2}^{\circ}-3 \mathrm{p}^{2}{ }^{4} \mathrm{P}_{5 / 2}$, which should be the strongest, has half of the regular intensity, while all other components closely follow the $L S$ coupling model. The exceptional component is blended by a component of another 
Table 3. Al I-intensity ratios within multiplets for the complex part of the Grotrian diagram.

\begin{tabular}{|c|c|c|c|c|c|}
\hline \multirow{3}{*}{$\begin{array}{l}\begin{array}{l}\text { Upper } \\
\text { level }\end{array} \\
3 \mathrm{~s} 3 \mathrm{p} 4 \mathrm{~s}{ }^{4} \mathrm{P}_{1 / 2}^{\mathrm{o}}\end{array}$} & \multirow{3}{*}{$\begin{array}{l}\begin{array}{l}\text { Lower } \\
\text { level }\end{array} \\
3 \mathrm{p}^{2{ }^{4}} \mathrm{P}_{1 / 2}\end{array}$} & \multirow{3}{*}{$\begin{array}{l}\lambda / \AA \\
3059.924\end{array}$} & \multicolumn{3}{|c|}{ Intensity ratio } \\
\hline & & & \multicolumn{2}{|c|}{ measured } & \multirow{2}{*}{$\frac{L S}{0.08}$} \\
\hline & & & 0.01 & $67 \%$ & \\
\hline & $3 \mathrm{p}^{2}{ }^{4} \mathrm{P}_{3 / 2}$ & 3064.290 & 0.14 & $43 \%$ & 0.40 \\
\hline \multirow{2}{*}{$3 \mathrm{~s} 3 \mathrm{p} 4 \mathrm{~s}{ }^{4} \mathrm{P}_{3 / 2}^{\mathrm{o}}$} & $3 \mathrm{p}^{2}{ }^{4} \mathrm{P}_{1 / 2}$ & 3054.679 & 0.02 & $53 \%$ & 0.04 \\
\hline & $3 \mathrm{p}^{2}{ }^{4} \mathrm{P}_{3 / 2}$ & 3059.029 & 0.01 & $40 \%$ & 0.13 \\
\hline \multirow{3}{*}{$3 \mathrm{~s} 3 \mathrm{p} 4 \mathrm{~s}^{4} \mathrm{P}_{5 / 2}^{\mathrm{o}}$} & $3 \mathrm{p}^{2}{ }^{4} \mathrm{P}$ & 3066.145 & 0.14 & $24 \%$ & 0.43 \\
\hline & $3 \mathrm{p}^{2}{ }^{4} \mathrm{P}_{3 / 2}$ & 3050.073 & 0.41 & $11 \%$ & 0.43 \\
\hline & $3 \mathrm{p}^{24} \mathrm{P}_{5 / 2}$ & 3057.144 & 1 & $25 \%$ & 1.00 \\
\hline \multirow[t]{2}{*}{$3 \mathrm{~s} 3 \mathrm{p} 3 \mathrm{~d}^{4} \mathrm{P}_{1 / 2}^{\mathrm{o}}$} & $3 \mathrm{p}^{2}{ }^{4} \mathrm{P}_{1 / 2}$ & 231 & 0.11 & $21 \%$ & 0.08 \\
\hline & $3 \mathrm{p}^{2}{ }^{4} \mathrm{P}_{3 / 2}$ & 2313.526 & 0.34 & $19 \%$ & 0.40 \\
\hline \multirow[t]{2}{*}{$3 \mathrm{~s} 3 \mathrm{p} 3 \mathrm{~d}^{4} \mathrm{P}_{3 / 2}^{\mathrm{o}}$} & $3 \mathrm{p}^{2}{ }^{4} \mathrm{P}_{1 / 2}$ & 2312.491 & 0.22 & $23 \%$ & 0.40 \\
\hline & $3 \mathrm{p}^{2}{ }^{4} \mathrm{P}_{3 / 2}$ & 2314.983 & 0.09 & $36 \%$ & 0.13 \\
\hline \multirow{3}{*}{$3 \mathrm{~s} 3 \mathrm{p} 3 \mathrm{~d}^{4} \mathrm{P}_{5 / 2}^{\mathrm{o}}$} & $3 \mathrm{p}^{24} \mathrm{P}_{5 / 2}$ & 2319.057 & 0.25 & $21 \%$ & 0.43 \\
\hline & $3 \mathrm{p}^{2}{ }^{4} \mathrm{P}_{3 / 2}$ & 2317.482 & 0.35 & $21 \%$ & 0.43 \\
\hline & $3 \mathrm{p}^{2}{ }^{4} \mathrm{P}_{5 / 2}$ & 2321.562 & 1 & $16 \%$ & 1.00 \\
\hline \multirow[t]{2}{*}{$3 \mathrm{~s} 3 \mathrm{p} 3 \mathrm{~d}^{4} \mathrm{D}_{1 / 2}^{\mathrm{o}}$} & $3 \mathrm{p}^{24} \mathrm{P}_{1 / 2}$ & 2368.112 & 0.20 & $24 \%$ & 0.21 \\
\hline & $3 \mathrm{p}^{2}{ }^{4} \mathrm{P}_{3 / 2}$ & 2370.726 & 0.05 & $39 \%$ & 0.04 \\
\hline \multirow[t]{3}{*}{$3 \mathrm{~s} 3 \mathrm{p} 3 \mathrm{~d}^{4} \mathrm{D}_{3 / 2}^{\mathrm{o}}$} & $3 \mathrm{p}^{2}{ }^{4} \mathrm{P}_{1 / 2}$ & 2367.611 & 0.23 & $35 \%$ & 0.21 \\
\hline & $3 \mathrm{p}^{2}{ }^{4} \mathrm{P}_{3 / 2}$ & 2370.225 & 0.27 & $30 \%$ & 0.27 \\
\hline & $3 \mathrm{p}^{2}{ }^{4} \mathrm{P}_{5 / 2}$ & 2374.496 & 0.03 & $44 \%$ & 0.03 \\
\hline \multirow[t]{2}{*}{$3 \mathrm{~s} 3 \mathrm{p} 3 \mathrm{~d}^{4} \mathrm{D}_{5 / 2}^{\mathrm{o}}$} & $3 \mathrm{p}^{2}{ }^{4} \mathrm{P}_{3 / 2}$ & 2369.304 & 0.57 & $15 \%$ & 0.52 \\
\hline & $3 \mathrm{p}^{2}{ }^{4} \mathrm{P}_{5 / 2}$ & 2373.571 & 0.22 & $30 \%$ & 0.23 \\
\hline $3 \mathrm{~s} 3 \mathrm{p} 3 \mathrm{~d}^{4} \mathrm{D}_{7 / 2}^{\mathrm{o}}$ & $3 \mathrm{p}^{2}{ }^{4} \mathrm{P}_{5 / 2}$ & 2372.070 & 0.50 & $17 \%$ & 1.00 \\
\hline
\end{tabular}

multiplet with much lower intensities, and the quoted intensity needed only a slight correction.

Considering all multiplets of the observed ionized aluminum (Table 4 ), the $L S$ coupling ratios are confirmed within the error brackets. Only principal multiplet lines $(\Delta J=1)$ have been observed.

In Table 5 we present Al II-branching ratios and transition probabilities obtained in this work. A special precaution was paid to the decay of the level $3 \mathrm{p}^{2}{ }^{1} \mathrm{D}_{2}$. Tayal $\&$ Hibbert (1984) calculated, because of severe cancelations, a very small oscillator strength for the line $3900.68 \AA$. The length form gives $7 \times 10^{-5}$, the velocity form $2 \times 10^{-5}$. We tentatively took the length form with the corresponding transition probability equal to $1.84 \times 10^{4} \mathrm{~s}^{-1}$. Then, from our branching ratios, the lifetime could be estimated to be $43 \mu \mathrm{s}$ (we cannot assign an error bracket due to an inherent uncertainty of the theoretical value; OP gives $7.47 \mu \mathrm{s}$, Butler et al. 1993). Four other theoretical treatments (Weiss 1967; Zare 1967; Victor et al. 1976; FroeseFischer \& Godefroid 1982) gave very disparate values of the same oscillator strength.

The OP data for this level are uncertain (Butler et al. 1993). The strong mixing of $3 \mathrm{p}^{2}$ and $3 \mathrm{~s} 3 \mathrm{~d}$ levels is the reason that the designation was not possible. This confirms the conclusion of Tayal \& Hibbert (1984).

For settling the query and to shed more light on the theoretical treatment, the measurement of the lifetime of the $3 \mathrm{p}^{2}{ }^{1} \mathrm{D}_{2}$ level would be very important.
Table 4. Al II-intensity ratios within multiplets.

\begin{tabular}{|c|c|c|c|c|c|}
\hline \multirow{2}{*}{$\begin{array}{l}\text { Upper } \\
\text { level }\end{array}$} & \multirow{2}{*}{$\begin{array}{l}\text { Lower } \\
\text { level }\end{array}$} & \multirow{2}{*}{$\lambda / \AA$} & \multicolumn{3}{|c|}{ Intensity ratio } \\
\hline & & & meas & red & $L S$ \\
\hline \multirow[t]{3}{*}{$3 \mathrm{p}^{21} \mathrm{D}_{2}$} & $3 \mathrm{p}^{1} \mathrm{P}_{1}^{\mathrm{o}}$ & 3900.675 & 8.04 & & \\
\hline & $3 \mathrm{p}^{3} \mathrm{P}_{1}^{\mathrm{o}}$ & 2081.481 & 0.68 & $9 \%$ & 0.6 \\
\hline & $3 \mathrm{p}^{3} \mathrm{P}_{2}^{\mathrm{o}}$ & 2086.864 & 1 & $5 \%$ & 1.0 \\
\hline $3 \mathrm{~d}^{\prime 3} \mathrm{~F}_{2}^{\mathrm{o}}$ & $3 d^{3} D_{1}$ & 2195.502 & 0.42 & $9 \%$ & 0.47 \\
\hline $3 \mathrm{~d}^{\prime 3} \mathrm{~F}_{3}^{\mathrm{o}}$ & $3 \mathrm{~d}^{3} \mathrm{D}_{2}$ & 2194.245 & 0.65 & $11 \%$ & 0.69 \\
\hline $3 \mathrm{~d}^{\prime 3} \mathrm{~F}_{4}^{\mathrm{o}}$ & $3 d^{3} D_{3}$ & 2192.604 & 1 & $8 \%$ & 1.00 \\
\hline $3 \mathrm{~d}^{\prime 3} \mathrm{~F}_{2}^{\mathrm{o}}$ & $4 d^{3} \mathrm{D}_{1}$ & 5100.34 & 0.44 & $19 \%$ & 0.47 \\
\hline $3 \mathrm{~d}^{\prime 3} \mathrm{~F}_{3}^{\mathrm{o}}$ & $4 d^{3} D_{2}$ & 5093.65 & 0.63 & $13 \%$ & 0.69 \\
\hline $3 \mathrm{~d}^{\prime 3} \mathrm{~F}_{4}^{\mathrm{o}}$ & $4 d^{3} D_{3}$ & 5085.02 & 1 & $8 \%$ & 1.00 \\
\hline $4 \mathrm{f}^{3} \mathrm{~F}_{2}^{\mathrm{o}}$ & $3 \mathrm{~d}^{3} \mathrm{D}_{1}$ & 3587.450 & 0.46 & $13 \%$ & 0.47 \\
\hline $4 \mathrm{f}^{3} \mathrm{~F}_{3}^{\mathrm{o}}$ & $3 d^{3} D_{2}$ & 3587.068 & 0.71 & $10 \%$ & 0.69 \\
\hline $4 \mathrm{f}^{3} \mathrm{~F}_{4}^{\mathrm{o}}$ & $3 \mathrm{~d}^{3} \mathrm{D}_{3}$ & 3586.557 & 1 & $4 \%$ & 1.00 \\
\hline $5 \mathrm{f}^{3} \mathrm{~F}_{2}^{\mathrm{o}}$ & $3 d^{3} D_{1}$ & 2638.690 & 0.51 & $12 \%$ & 0.47 \\
\hline $5 \mathrm{f}^{3} \mathrm{~F}_{3}^{\mathrm{o}}$ & $3 d^{3} D_{2}$ & 2638.155 & 0.60 & $18 \%$ & 0.69 \\
\hline $5 \mathrm{f}^{3} \mathrm{~F}_{4}^{\mathrm{o}}$ & $3 \mathrm{~d}^{3} \mathrm{D}_{3}$ & 2637.689 & 1 & $8 \%$ & 1.00 \\
\hline $6 \mathrm{f}^{3} \mathrm{~F}_{2}^{\mathrm{o}}$ & $3 d^{3} D_{1}$ & 2326.406 & 0.43 & $24 \%$ & 0.47 \\
\hline $6 \mathrm{f}^{3} \mathrm{~F}_{3}^{\mathrm{o}}$ & $3 d^{3} D_{2}$ & 2325.494 & 0.68 & $16 \%$ & 0.69 \\
\hline $6 \mathrm{f}^{3} \mathrm{~F}_{4}^{\mathrm{o}}$ & $3 d^{3} D_{3}$ & 2324.199 & 1 & $13 \%$ & 1.00 \\
\hline $6 \mathrm{f}^{3} \mathrm{~F}_{2}^{\mathrm{o}}$ & $4 d^{3} D_{1}$ & 5867.81 & 0.48 & $39 \%$ & 0.47 \\
\hline $6 \mathrm{f}^{3} \mathrm{~F}_{3}^{\mathrm{o}}$ & $4 d^{3} D_{2}$ & 5861.53 & 0.62 & $39 \%$ & 0.69 \\
\hline $6 \mathrm{f}^{3} \mathrm{~F}_{4}^{\mathrm{o}}$ & $4 d^{3} D_{3}$ & 5853.62 & 1 & $26 \%$ & 1.00 \\
\hline $7 \mathrm{f}^{3} \mathrm{~F}_{2}^{\mathrm{o}}$ & $3 \mathrm{~d}^{3} \mathrm{D}_{1}$ & 2095.140 & 0.48 & $19 \%$ & 0.47 \\
\hline $7 \mathrm{f}^{3} \mathrm{~F}_{3}^{\mathrm{o}}$ & $3 d^{3} D_{2}$ & 2094.790 & 0.67 & $13 \%$ & 0.69 \\
\hline $7 \mathrm{f}^{3} \mathrm{~F}_{4}^{\mathrm{o}}$ & $3 d^{3} D_{3}$ & 2094.264 & 1 & $10 \%$ & 1.00 \\
\hline
\end{tabular}

The decay of the $3 \mathrm{p} 3 \mathrm{~d}^{3} \mathrm{~F}^{\mathrm{o}}\left(3 \mathrm{~d}^{\prime}{ }^{3} \mathrm{~F}^{\mathrm{o}}\right)$ term has several channels into four lower terms $n \mathrm{~d}^{3} \mathrm{D}(n=3-6)$. Therefore only a tentative upper limit to transition probabilities could be set for the measured spectral lines. We compared the maximum possible experimental value with the theory of Chang \& Wang (1987). The lifetimes obtained by the beam foil method suffer from statistical errors larger than $10 \%$.

Wiese \& Martin (1980) have quoted transition probabilities of ionized aluminum of only two spectral lines in the range from $2000-6000 \AA$, and no line of our Table 5 is on their list.

4f ${ }^{3} \mathrm{~F}$ sublevels can depopulate to $3 \mathrm{~d}$ and $4 \mathrm{~d}^{3} \mathrm{D}$ sublevels, but transitions to $n=4$ are further in the infrared region and likely very weak. It is interesting that there was also a very weak transition from $4 \mathrm{f}^{3} \mathrm{~F}_{3}^{\circ}$ to $3 \mathrm{p}^{2}{ }^{1} \mathrm{D}_{2}$, but on the verge of perception. The line $3586.557 \AA$ is the only transition from the $4 \mathrm{f}^{3} \mathrm{~F}_{4}^{\circ}$ sublevel and has no error assigned.

Terms $5 \mathrm{f}^{3} \mathrm{~F}^{\circ}$, 6f ${ }^{3} \mathrm{~F}^{\circ}$, $7 \mathrm{f}^{3} \mathrm{~F}^{\circ}$ can depopulate to several lower terms and we can give only an estimate of the upper limit of transition probabilities of some lines. A comparison of these upper estimates with theoretically derived 
Table 5. Al II-branching ratios and transition probabilities $\left(A_{k i}\right)$. The value for the transition probability of the $\mathrm{Al}$ II $3900.675 \AA$ line was taken over from the work of Tayal \& Hibbert (1984) (for procedure see discussion in text).

\begin{tabular}{|c|c|c|c|c|c|c|c|c|}
\hline $\begin{array}{l}\text { Upper } \\
\text { level }\end{array}$ & $\begin{array}{l}\text { Lower } \\
\text { level }\end{array}$ & $\lambda / \AA$ & \multicolumn{2}{|c|}{$\begin{array}{l}\text { Branching } \\
\text { ratio }\end{array}$} & this wo & & \multicolumn{2}{|c|}{$\begin{array}{l}A_{k i} / 10^{8} \mathrm{~s}^{-1} \\
\text { other authors }\end{array}$} \\
\hline \multirow[t]{3}{*}{$3 \mathrm{p}^{2}{ }^{1} \mathrm{D}_{2}$} & $3 \mathrm{p}^{1} \mathrm{P}_{1}^{\mathrm{o}}$ & 3900.675 & 0.79 & $13 \%$ & \multicolumn{4}{|c|}{$1.84 \times 10^{-4}$} \\
\hline & $3 \mathrm{p}^{3} \mathrm{P}_{1}^{\mathrm{o}}$ & 2081.481 & 0.08 & $48 \%$ & \multicolumn{4}{|c|}{$0.19 \times 10^{-4}$} \\
\hline & $3 \mathrm{p}^{3} \mathrm{P}_{2}^{\mathrm{o}}$ & 2086.864 & 0.13 & $42 \%$ & \multicolumn{4}{|c|}{$0.30 \times 10^{-4}$} \\
\hline \multirow[t]{2}{*}{$3 \mathrm{~d}^{3} \mathrm{~F}_{2}^{\mathrm{o}}$} & $3 \mathrm{~d}^{3} \mathrm{D}_{1}$ & 2195.502 & 0.70 & $13 \%$ & \multicolumn{2}{|l|}{$<2$} & 2.14 & Chang \& Wang (1987) \\
\hline & $4 d^{3} D_{1}$ & 5100.34 & 0.30 & $31 \%$ & \multicolumn{2}{|l|}{$<0.85$} & 0.012 & Chang \& Wang (1987) \\
\hline \multirow[t]{2}{*}{$3 \mathrm{~d}^{3} \mathrm{~F}_{3}^{\mathrm{o}}$} & $3 \mathrm{~d}^{3} \mathrm{D}_{2}$ & 2194.245 & 0.76 & $13 \%$ & \multicolumn{2}{|l|}{$<2.2$} & 2.25 & Chang \& Wang (1987) \\
\hline & $4 \mathrm{~d}^{3} \mathrm{D}_{2}$ & 5093.65 & 0.24 & $40 \%$ & \multicolumn{2}{|l|}{$<0.7$} & 0.013 & Chang \& Wang (1987) \\
\hline \multirow[t]{2}{*}{$3 \mathrm{~d}^{3} \mathrm{~F}_{4}^{\mathrm{o}}$} & $3 \mathrm{~d}^{3} \mathrm{D}_{3}$ & 2192.604 & 0.72 & $10 \%$ & \multicolumn{2}{|l|}{$<2.1$} & 2.54 & Chang \& Wang (1987) \\
\hline & $4 d^{3} \mathrm{D}_{3}$ & 5085.02 & 0.28 & $26 \%$ & \multicolumn{2}{|l|}{$<0.8$} & 0.015 & Chang \& Wang (1987) \\
\hline \multirow[t]{3}{*}{$4 \mathrm{f}^{3} \mathrm{~F}_{2}^{\mathrm{o}}$} & $3 \mathrm{~d}^{3} \mathrm{D}_{1}$ & 3587.450 & 0.98 & $3 \%$ & \multirow[t]{3}{*}{$<1.55$} & \multirow[t]{3}{*}{$>11 \%$} & \multirow[t]{3}{*}{1.98} & \multirow[t]{3}{*}{ Chang \& Wang (1987) } \\
\hline & $3 \mathrm{~d}^{3} \mathrm{D}_{2}$ & 3587.3 & 0.02 & $100 \%$ & & & & \\
\hline & $3 \mathrm{~d}^{3} \mathrm{D}_{3}$ & 3587.1 & $\approx 0$ & & & & & \\
\hline \multirow[t]{3}{*}{$4 \mathrm{f}^{3} \mathrm{~F}_{3}^{\mathrm{o}}$} & $3 \mathrm{~d}^{3} \mathrm{D}_{2}$ & 3587.068 & 0.96 & $5 \%$ & \multirow[t]{3}{*}{$<1.55$} & \multirow[t]{3}{*}{$>13 \%$} & \multirow[t]{3}{*}{2.07} & \multirow[t]{3}{*}{ Chang \& Wang (1987) } \\
\hline & $3 \mathrm{~d}^{3} \mathrm{D}_{3}$ & 3587.9 & 0.04 & $100 \%$ & & & & \\
\hline & $3 \mathrm{p}^{2}{ }^{1} \mathrm{D}_{2}$ & 2635.020 & $\approx 0$ & & & & & \\
\hline $4 \mathrm{f}^{3} \mathrm{~F}_{4}^{\mathrm{o}}$ & $3 \mathrm{~d}{ }^{3} \mathrm{D}_{3}$ & 3586.557 & & & $<1.55$ & & 2.33 & Chang \& Wang (1987) \\
\hline $5 \mathrm{f}^{3} \mathrm{~F}_{2}^{\mathrm{o}}$ & $3 \mathrm{~d}^{3} \mathrm{D}_{1}$ & 2638.690 & $\approx 1.00$ & & $<0.7$ & & 0.25 & Chang \& Wang (1987) \\
\hline $5 \mathrm{f}^{3} \mathrm{~F}_{3}^{\mathrm{o}}$ & $3 \mathrm{~d}^{3} \mathrm{D}_{2}$ & 2638.255 & $\approx 1.00$ & & $<0.7$ & & & \\
\hline $5 \mathrm{f}^{3} \mathrm{~F}_{4}^{\mathrm{o}}$ & $3 \mathrm{~d}^{3} \mathrm{D}_{3}$ & 2637.689 & $\approx 1.00$ & & $<0.7$ & & 0.29 & Chang \& Wang (1987) \\
\hline \multirow[t]{2}{*}{$6 \mathrm{f}^{3} \mathrm{~F}_{2}^{\mathrm{o}}$} & $3 \mathrm{~d}^{3} \mathrm{D}_{1}$ & 2326.496 & 0.18 & $26 \%$ & $<0.12$ & & 0.31 & Chang \& Wang (1987) \\
\hline & $4 \mathrm{~d}^{3} \mathrm{D}_{1}$ & 5867.81 & 0.82 & $6 \%$ & $<0.54$ & & 0.10 & Chang \& Wang (1987) \\
\hline \multirow[t]{2}{*}{$6 \mathrm{f}^{3} \mathrm{~F}_{3}^{\mathrm{o}}$} & $3 \mathrm{~d}^{3} \mathrm{D}_{2}$ & 2325.494 & 0.32 & $15 \%$ & $<0.21$ & & 0.33 & Chang \& Wang (1987) \\
\hline & $4 d^{3} \mathrm{D}_{2}$ & 5861.53 & 0.68 & $7 \%$ & $<0.45$ & & 0.11 & Chang \& Wang (1987) \\
\hline \multirow[t]{2}{*}{$6 \mathrm{f}^{3} \mathrm{~F}_{4}^{\mathrm{o}}$} & $3 \mathrm{~d}^{3} \mathrm{D}_{3}$ & 2324.199 & 0.41 & $20 \%$ & $<0.27$ & & 0.37 & Chang \& Wang (1987) \\
\hline & $4 \mathrm{~d}^{3} \mathrm{D}_{3}$ & 5853.62 & 0.59 & $20 \%$ & $<0.39$ & & 0.12 & Chang \& Wang (1987) \\
\hline \multirow[t]{2}{*}{$7 \mathrm{f}^{3} \mathrm{~F}_{2}^{\mathrm{o}}$} & $3 \mathrm{~d}^{3} \mathrm{D}_{1}$ & 2095.140 & 0.97 & $7 \%$ & $<2$ & & 1.47 & Chang \& Wang (1987) \\
\hline & $4 \mathrm{~d}^{3} \mathrm{D}_{1}$ & 4589.742 & 0.03 & $100 \%$ & & & & \\
\hline $7 \mathrm{f}^{3} \mathrm{~F}_{3}^{\mathrm{o}}$ & $3 \mathrm{~d}^{3} \mathrm{D}_{2}$ & 2094.790 & 0.98 & $4 \%$ & $<2$ & & 1.57 & Chang \& Wang (1987) \\
\hline & $4 \mathrm{~d}^{3} \mathrm{D}_{2}$ & 4588.191 & 0.02 & $100 \%$ & & & & \\
\hline $7 \mathrm{f}^{3} \mathrm{~F}_{4}^{\mathrm{o}}$ & $3 \mathrm{~d}^{3} \mathrm{D}_{3}$ & 2094.264 & 0.98 & $3 \%$ & $<2$ & & 1.74 & Chang \& Wang (1987) \\
\hline & $4 \mathrm{~d}^{3} \mathrm{D}_{3}$ & 4585.817 & 0.02 & $100 \%$ & & & & \\
\hline
\end{tabular}

transition probabilities (Chang \& Wang 1987) shows, in some cases, the inadequacy of the calculated values. It should be noted that we found the depopulation branches $6 \mathrm{f}^{3} \mathrm{~F}^{\circ}-3 \mathrm{~d}^{3} \mathrm{D}$ less intense than branches to the higher term $6 \mathrm{f}^{3} \mathrm{~F}^{\circ}-4 \mathrm{~d}^{3} \mathrm{D}$, in contrast to the calculations of Chang \& Wang (1987).

For convenience we added, in Table 6, transition probabilities for some prominent lines which we derived from selected literature data. The lifetime of the triplet metastable level $3 \mathrm{p}^{3} \mathrm{P}_{1}^{\mathrm{o}}$ has an accuracy within $1 \%$ as is shown by agreeing experimental results (Table 1 ). As it is mentioned above, the lifetime of the singlet resonant level $3 \mathrm{p}^{1} \mathrm{P}_{1}^{\circ}$ presented in Table 1 is the average value of the experimental data with an accuracy within $2 \%$.
In a similar way we noted the agreement between different theoretical approaches resulting in the transition probabilities of the Al II spectral lines $2816.185 \AA$ $\left(4 \mathrm{~s}^{1} \mathrm{~S}_{0}-3 \mathrm{p}{ }^{1} \mathrm{P}_{1}^{\circ}\right), \quad 1990.531 \quad \AA \quad\left(3 \mathrm{~d}{ }^{1} \mathrm{D}_{2}-3 \mathrm{p} \quad{ }^{1} \mathrm{P}_{1}^{\circ}\right)$ and $4663.056 \AA\left(4 \mathrm{p}^{1} \mathrm{P}_{1}^{\circ}-3 \mathrm{p}^{2}{ }^{1} \mathrm{D}_{2}\right)$.

\section{Conclusion}

In most cases we approved $L S$ intensity ratios. Known lifetimes gave us the possibility to evaluate absolute transition probabilities, either by using the branching ratios we measured, or using those found in the literature. We mostly justified $L S$ ratios with some error and are tempted to consider intensity ratios within multiplets equal to the theoretical ones. Accounting for the inevitable 
Table 6. Al II-transition probabilities $\left(A_{k i}\right)$ calculated using results of other authors. If more than one source is cited, an average of the transition probabilities was taken.

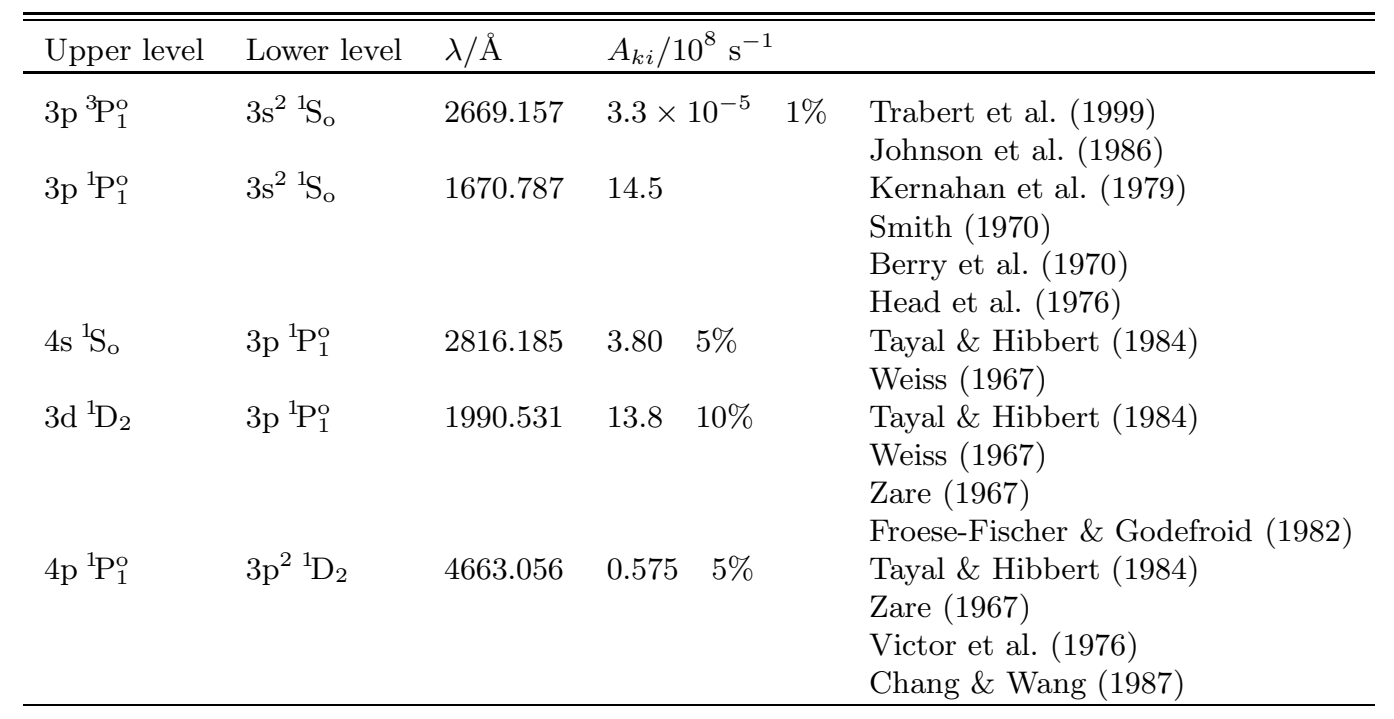

experimental error of intensity ratios, and adding it to the error of lifetimes, we likely overestimate the error of the transition probabilities. The question is, can we deliberately consider the intensity ratios equal to the theoretical ones? We found some deviations from $L S$ ratios, sometimes caused by autoionization. Puzzling deviation is found in neutral aluminum for the component $3 \mathrm{~s} 3 \mathrm{p}{ }^{4} \mathrm{D}_{7 / 2}^{\circ}-3 \mathrm{p}^{2}{ }^{4} \mathrm{P}_{5 / 2}$, which instead of being the most intense, acquires only half of its regular relative intensity.

Our study showed the importance of further lifetime measurements. Transitions arising from the complex part of the neutral aluminum term diagram are prominent and well resolved, and could serve for diagnostic purposes, but lifetimes of $3 \mathrm{~s} 3 \mathrm{p} 4 \mathrm{~s}{ }^{4} \mathrm{P}^{\circ}, 3 \mathrm{~s} 3 \mathrm{p} 3 \mathrm{~d}{ }^{4} \mathrm{P}^{\circ}$ and $3 \mathrm{~s} 3 \mathrm{p} 3 \mathrm{~d}{ }^{4} \mathrm{D}^{\circ}$ are missing. Only theoretical OP data exist (Mendoza et al. 1995), but not for all of these states (for example $\left.3 \mathrm{~s} 3 \mathrm{p} 3 \mathrm{~d}^{4} \mathrm{D}^{0}\right)$. For ionized aluminum, especially because of the problems associated with the cancelation of integrals during the calculations, the experimental lifetime of $3 \mathrm{p}^{2}{ }^{1} \mathrm{D}_{2}$ is urgently needed.

\section{References}

Andersen, T., Jensen, K. A., \& Sørensen, G. 1969, J. Opt. Soc. Am., 59, 1197

Andersen, T., Roberts, J. R., \& Sørensen, G. 1971, Phys. Scri., 4,52

Baudinet-Robinet, Y., Dumont, R. D., Garnir, H. P., Biemont, E., \& Grevesse, N. 1979, J. Phys., C1, S2, 40, 127

Berry, H. G., Bromander, J., \& Buchta, R. 1970, Phys. Scrip., 1,181

Butler, K., Mendoza, C., \& Zeippen, C. 1993, J. Phys. B, 26, 4409

Buurman, E., Dönszelmann, A., Hansen, J. E., \& Snoek, C. 1986, A\&A, 164, 224

Buurmann, E., \& Dönszelmann, A. 1990, A\&A, 227, 289

Chang, T. N., \& Fang, T. K. 1995, Phys. Rev. A, 52, 2638

Chang, T. N., \& Wang, R. 1987, Phys. Rev. A, 36, 3535
Chou, H. S., Chi, H. C., \& Huang, K. N. 1973, J. Phys. B, 26, 4079

Cowan, R. D., Hobbs, L. M., \& York, D. G. 1982, ApJ, 257, 373

Crespo Lopez-Urrutia, J. R., Neger, T., \& Jäger, H. 1994, J. Phys. D: Appl. Phys., 27, 994

Cunningham, P. T. 1968, J. Opt. Soc. Am., 58, 1507

Das, B. P., \& Idrees, M. I. 1990, Phys. Rev. A, 42, 6900

Davidson, M. D., Volten, H., \& Dönszelmann, A. 1990, A\&A, 238,452

Eriksson, K. B., \& Isberg, B. S. 1962, Arkiv för Fysik, 23, 527

Froese-Fischer, C., \& Godefroid, M. 1982, Nucl. Instrum. Meth., 202, 307

Fuhr, J. R., \& Wiese, W. L. 1996, in CRC Handbook of Chemistry and Physics 77th ed., Ch. 10, ed. D. Lide, \& H. Frederikse (Boca Raton, Fl: CRC Press Inc.), 128

Hannaford, P., \& Lowe, R. H. 1981, J. Phys. B, 14, L5

Head, M. E. M., Head, C. E., \& Lawrence, J. N. 1976, in Atomic Structure and Lifetimes, ed. F. A. Sellin, \& D. J. Pegg (NY: Plenum), 147

Hibbert, A., \& Keenan, F. P. 1987, J. Phys. B, 20, 4693

Huang, K., \& Johanson, W. R. 1985, NIM B, 9, 509

Johnson, B. C., Smith, P. L., \& Parkinson, W. H. 1986, ApJ, 308, 1013

Jönsson, G., Kröll, S., Lundberg, H., \& Svanberg, S. 1984, Z. Phys. A, 316, 259

Jönsson, G., \& Lundberg, H. 1983, Z. Phys. A, 313, 151

Jonsson, P., \& Froese-Fisher, C. 1997, J. Phys. B, 30, 5861

Kaufman, V., \& Martin, W. C. 1991, J. Phys. Chem. Ref. Data, 20, 775

Kernahan, J. A., Pinnington, E. H., O'Neill, J. A., Brooks, R. L., \& Donnely, K. E. 1979, Phys. Scri., 19, 267

Klose, J. Z. 1997, Phys. Rev. A, 19, 678

Laughlin, C., \& Victor, G. A. 1979, ApJ, 234, 407

Lavin, C., Alvarez, A., \& Martin, I. 1997, J. Quantum Spectroscopy Radiat. Transfer, 57, 831

Lombardi, G., Cardon, B. L., \& Kurucz, R. L. 1981, ApJ, 248, 1202

Marcinek, R., \& Migdalek, J. 1993, J. Phys. B, 26, 1391

Marek, J., \& Richter, J. 1973, A\&A, 26, 155 
Mendoza, C., Eissner, W., Le Dourneuf, M., \& Zeippen, C. J. Trabert, E., Wolf, A., \& Linkemann, J. 1999, J. Phys. B, 32, 1995, J. Phys. B, 28, 3485

Ozdemir, L., \& Karal, H. 1997, J. Quantum Spectroscopy Radiat. Transfer, 62, 655

Smith, W. H. 1970, NIM, 90, 115

Smith, W. H., \& Liszt, H. S. 1971, J. Opt. Soc. Am., 61, 938

Stanek, M., Glowacki, L., \& Migdalek, J. 1996, J. Phys. B, 29, 2985

Tayal, S. S., \& Hibbert, A. 1984, J. Phys. B, 17, 3835

Taylor, P. R. C. W., Bauschlicher, J., \& Langhoff, S. 1988, J. Phys. B, 21, L333

Theodosiou, C. E. 1992, Phys. Rev. A, 45, 7756 637

Trefftz, E. 1988, J. Phys. B., 21, 1761

Victor, G. A., Stewart, R. F., \& Laughlin, C. 1976, ApJS, 31, 237

Weiss, A. W. 1967, J. Chem. Phys., 47, 3573

Weiss, A. W. 1974, Phys. Rev. A, 9, 1525

Wiese, W. L., \& Martin, G. A. 1980, Transition Probabilities, Part II, Vol. Natl. Stand. Ref. Data System., Natl. Bur. Std. 68 (Washington DC)

Zare, R. N. 1967, J. Chem. Phys., 47, 3561

Zon, Y., \& Froese-Fisher, C. 2001, J. Phys. B, 34, 915 